Rapid Communications

\title{
Micro Total Bioassay System for Oral Drugs: Evaluation of Gastrointestinal Degradation, Intestinal Absorption, Hepatic Metabolism, and Bioactivity
}

\author{
Yuki ImURa,* Etsuro Yoshimura,* and Kiichi SATO*,**† \\ *Department of Applied Biological Chemistry, School of Agricultural and Life Science, The University of Tokyo, \\ 1-1-1 Yayoi, Bunkyo, Tokyo 113-8657, Japan \\ **Department of Chemistry and Chemical Biology, School of Engineering, Gunma University, 1-5-1 Tenjin, \\ Kiryu, Gunma 376-8515, Japan
}

\begin{abstract}
A micro total bioassay system that mimics physiological processes was developed as a means of evaluating orally administered drugs. A new feature accounting for gastrointestinal digestion was added to the previous system, which consists of microintestine, microliver, and target components. The artificial micro-gastrointestinal tract employs synthetic digestive juices. The system could correctly assay the overall digestive properties of ingested anticancer agents, i.e., the stability during digestive processes, as well as intestinal absorption, hepatic metabolism, and bioactivity toward target cells.
\end{abstract}

(Received February 3, 2012; Accepted February 9, 2012; Published March 10, 2012)

\begin{abstract}
Oral medicines show their effects only after gastrointestinal (GI) digestion, intestinal absorption, and hepatic metabolism. GI digestion by gastric acid and/or enzymatic degradation often deactivates oral drugs. Thus, the stability must be tested during drug development using artificial digestive juices. Bioassays using cultured cells are often used to evaluate intestinal absorption, hepatic metabolism, physiological activity, and so on. ${ }^{1-5}$ In conventional bioassays, however, only one bioactivity can be examined. Moreover, these systems are unnaturally large, given the scale of the cells, and testing can take considerable time. The rate at which new candidate drugs are being discovered is very high. Therefore, evaluation methods featuring high throughput, low cost, and ease of use are required. One of the ways to fulfill this requirement is miniaturization. Methods have been established for culturing cells on a microchip under microflow conditions ${ }^{6,7}$ and for performing bioassays in a microdevice. ${ }^{8-11}$ We previously described a total micro bioassay system to evaluate intestinal absorption, hepatic metabolism, and bioactivity against breast-cancer cells. ${ }^{12}$ That system employed human intestinal model cell line Caco-2 as an intestine model, human hepatocellular carcinoma cells HepG2 as a liver model, and human breast carcinoma cells MCF-7 as a target tissue. In the current study, a new feature was added to the system to account for GI digestion. The system described below integrates four components: a microGI tract, a microintestine, a microliver, and target cells, into a single microchip. This preliminary micro total bioassay system was used to determine the effects of digestion, intestinal absorption, and hepatic metabolism on the bioactivity of two known anticancer prodrugs: cyclophosphamide (CPA) ${ }^{13}$ and tegafur (TGF). ${ }^{14}$

Detailed microchip fabrication procedures have been described previously. ${ }^{11,12}$ The depth of the horizontal microchannel was $200 \mu \mathrm{m}$, and the diameter of the vertical microchannel was
\end{abstract}

$\dagger$ To whom correspondence should be addressed.

E-mail: kiichi.sato@gunma-u.ac.jp
$1.6 \mathrm{~mm}$. The bottom membranes of BioCoat fibrillar collagen type I six-well plate 1.0- $\mu \mathrm{m}$ inserts (BD Biosciences, San Jose, $\mathrm{CA})$ were cut to the appropriate size and used for cell culture support to create a microintestine with Caco-2 cells. All solutions were pumped with a microsyringe pump (KDS230; KD Scientific, Holliston, MA). The contents and injection flow rates of the solutions are summarized in Table $1 . \quad$ Fluids identical to those used in disintegration tests ${ }^{15}$ were used as artificial digestive juices.

The Caco-2 cells were cultured in the microchip on a collagen-coated membrane 3 days prior to the assay. The HepG2 cells were seeded on Cytodex-3 microcarriers (GE Healthcare, Buckinghamshire, UK) for 5 days, and packed in the microchip immediately before the assay. The MCF-7 cells were cultured on the fibronectin-coated glass surface of the microchannel overnight. All cells in the microchip were cultured in Dulbecco's modified Eagle's medium (DMEM) supplemented with $10 \%$ fetal bovine serum (FBS) and $1 \%$ nonessential amino acid (NEAA) solution at $37^{\circ} \mathrm{C}$ in a humidified atmosphere of $5 \% \mathrm{CO}_{2}$. As an indicator of cell viability, the resazurin-converting activity was determined using the CellTiter-Blue cell viability assay reagent (Promega, Madison, WI). ${ }^{16}$

The micro total bioassay chip consists of two microchannels (Fig. 1). The upper microchannel mimics the human GI tract, and the lower channel mimics a blood vessel. The sample solution was first mixed with the artificial gastric juice in the microstomach. This process reduced the solution $\mathrm{pH}$ to about 2, as measured with $\mathrm{pH}$ test papers (Toyo Roshi Kaisha, Tokyo, Japan). The resulting solution was neutralized, and then mixed with artificial intestinal juice in the microduodenum before flowing into the microintestine. If the sample was able to permeate the Caco-2 layer of the microintestine, then it moved into the lower channel. This implies that the sample would be absorbed into the human body. The absorbed sample was moved to the microliver, which contained Cytodex beads with 
Table 1 Contents and injection flow rates of the solutions

\begin{tabular}{cllr}
\hline Solution & & \multicolumn{1}{c}{ Content } & Injection flow rate/nL min ${ }^{-1}$ \\
\hline a & Sample solution & $5 \mathrm{mM} \mathrm{CPA}$ or $25 \mathrm{mM} \mathrm{TGF}$ & 200 \\
$\mathrm{~b}$ & Gastric juice & $100 \mathrm{mM} \mathrm{HCl}, 50 \mathrm{mM} \mathrm{NaCl}$ & 57 \\
$\mathrm{c}$ & Neutralization buffer & $100 \mathrm{mM} \mathrm{NaOH}, 20 \mathrm{mM} \mathrm{Na} \mathrm{HPO}_{4}$ & 57 \\
$\mathrm{~d}$ & Intestinal juice & $50 \mathrm{mM} \mathrm{K} \mathrm{HPO}_{4}, 24 \mathrm{mM} \mathrm{NaOH}, 80 \mathrm{mM} \mathrm{NaCl}, 0.3 \%$ bile extract & 57 \\
$\mathrm{e}$ & Medium (upper channel) & DMEM, 10\% FBS, 1\% NEAA & 200 \\
$\mathrm{~g}$ & Medium (lower channel) & DMEM, 10\% FBS, 1\% NEAA & 400 \\
\hline
\end{tabular}

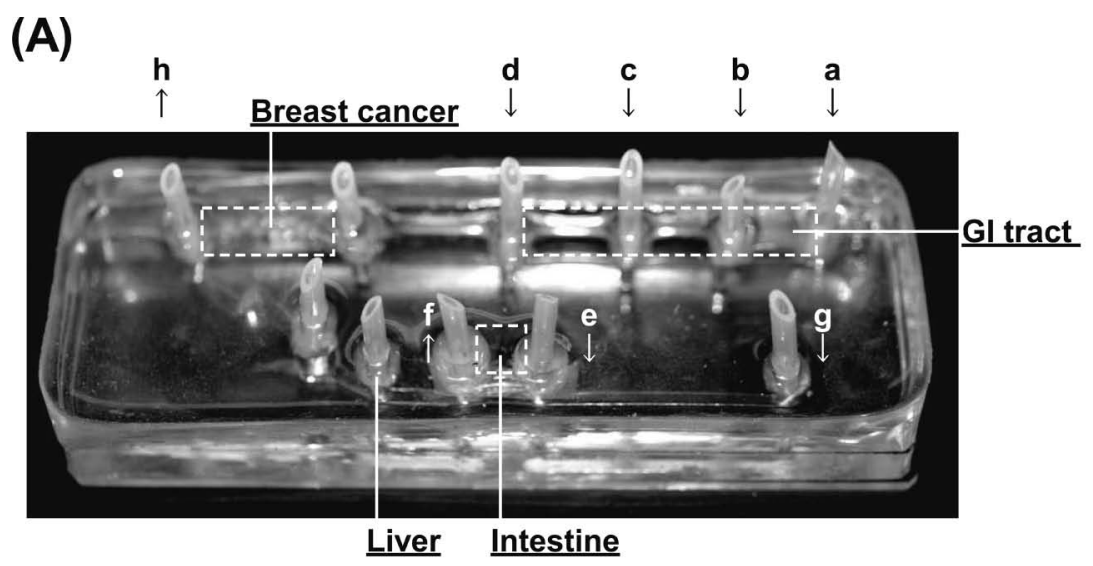

(B)

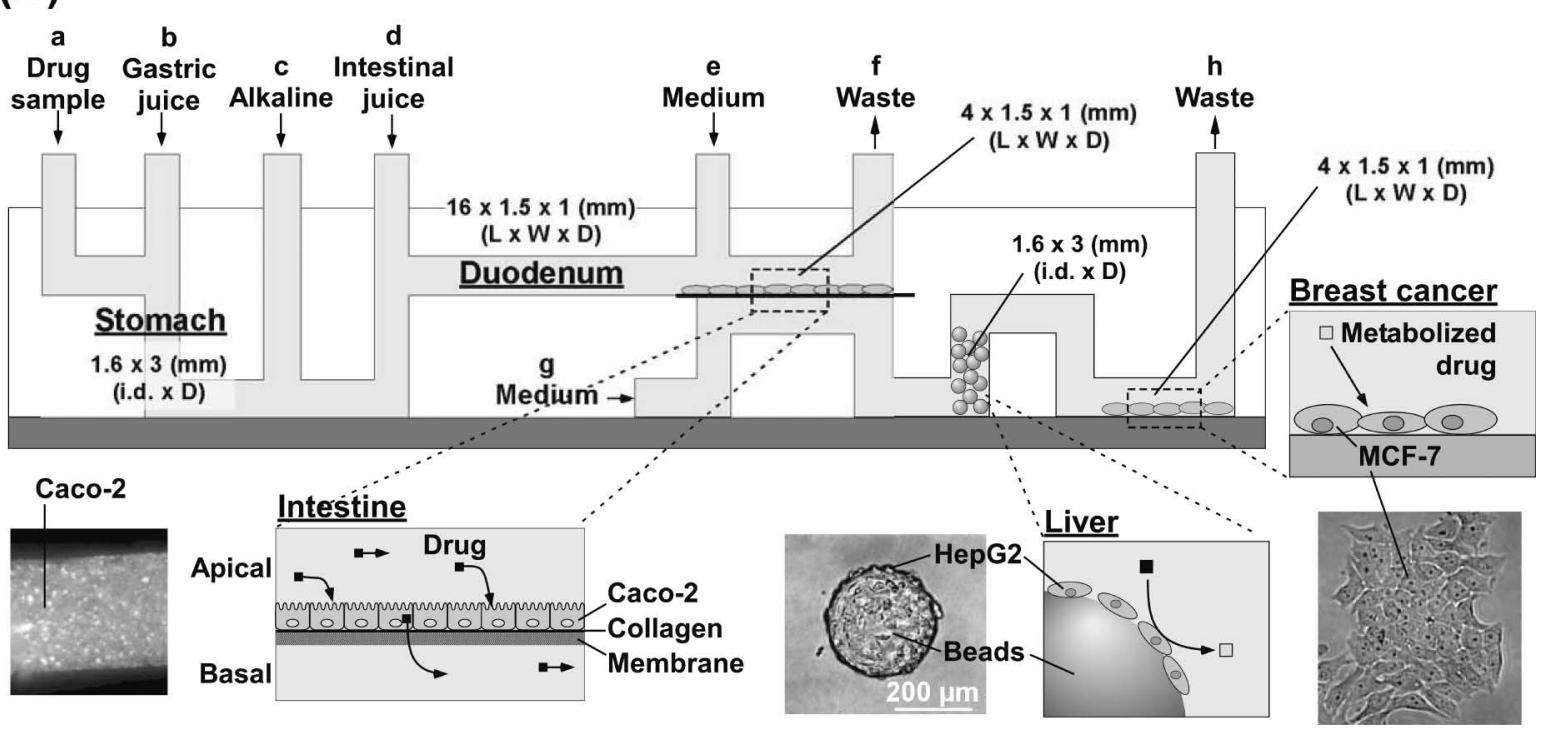

Fig. 1 (A) Photograph and (B) cross-sectional illustration of the micro total bioassay system. The figure is not to scale.

HepG2 cells, where it was metabolized. Finally, the sample reached the target MCF-7 cells and exerted its bioactivity on the cells. After 2 days of culturing, the total bioactivity was evaluated by measuring the viability of the target breast cancer cells. To determine the properties of the sample compound, experiments were also performed without digestive processes, Caco- 2 cells or HepG2 cells. When digestive processes were not manifest, the sample was not broken down. When the Caco-2 cells were absent, the sample freely passed through the membrane and entered the lower channel by diffusion. Without HepG2 cells, the sample was not metabolized.

Figure 2 shows the results of the micro total bioassay using
$5 \mathrm{mM} \mathrm{CPA}$ and $25 \mathrm{mM}$ TGF. In control experiments without anticancer agents, the viability of MCF-7 cells increased by $17 \%$ after 2 days of culturing as a result of cell proliferation. In test experiments, CPA was highly active in the presence of HepG2 cells, implying that it was activated by hepatic metabolism. Conversely, Caco-2 cells seemed to have little effect on the CPA activity, and the drug easily crossed the microintestine layer. CPA was stable during the digestive processes, which had little effect on the activity of the drug. The results for TGF, another anticancer agent, were strikingly different. In the absence of digestion processes, TGF exhibited similar qualities as those of CPA. TGF was highly active only 
(A)

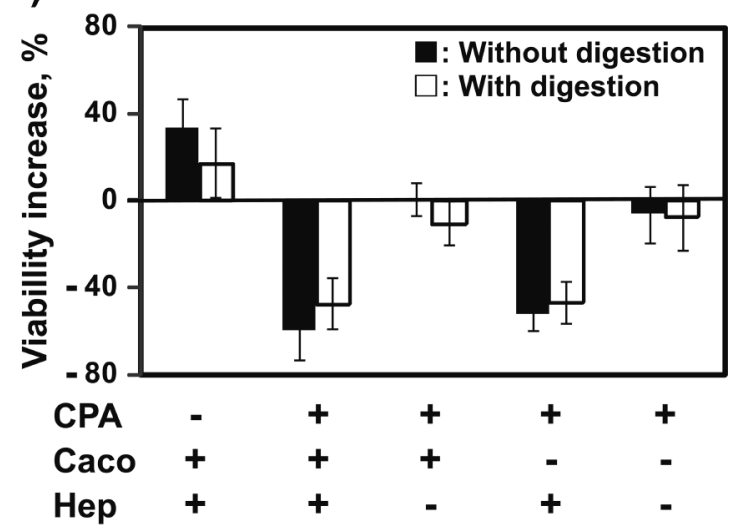

(B)

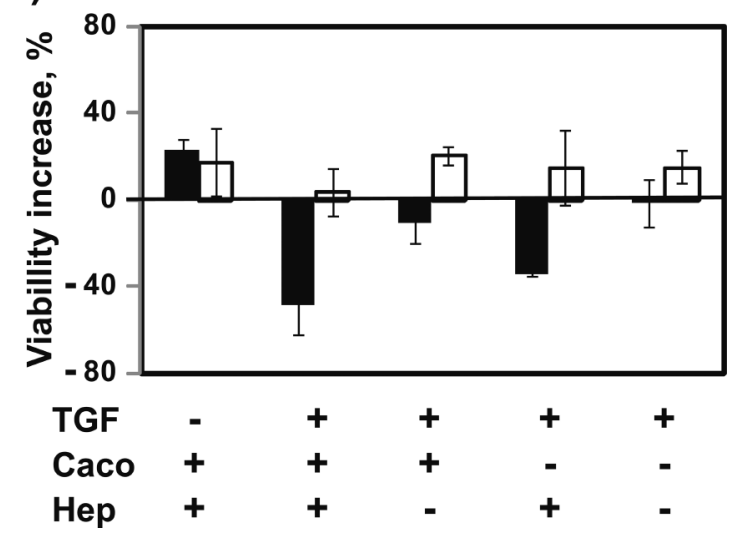

Fig. 2 Viability changes in target MCF-7 cells treated with anticancer agents, as measured by the micro total bioassay system. The bioactivity was estimated from the ratio of the viability of MCF-7 cells incubated with the samples for 2 days to that before a treatment $(n=3)$. The samples assayed contained (A) $5 \mathrm{mM} \mathrm{CPA}$ and (B) $25 \mathrm{mM}$ TGF.

after metabolism, and permeated easily through the Caco- 2 cell layer. However, with the inclusion of digestion processes, the anticancer activity of TGF was lost in all cases, indicating that the drug was damaged or had been degraded. These results are consistent with the known properties of these drugs. ${ }^{13,17}$ Both CPA and TGF are typical prodrugs, showing strong activity only after hepatic metabolism. TGF is an alkaline drug that can be neutralized by gastric juices. Thus, the micro total bioassay system correctly evaluated the effects of gastric degradation, as well as the permeation and metabolism of these known substances.

The various aspects of the micro total bioassay system described herein were controlled with a single microsyringe pump, thus eliminating the human labor, and many of the sources of error inherent in pipetting. Moreover, this system required only $20 \%$ of the Caco- 2 and MCF-7 cells, and $10 \%$ of the sample volume and reagents, required by conventional in-vitro assays. All processes in the micro total bioassay system were performed in parallel. Thus, the total assay time was reduced from the 3 days required for conventional in-vitro assays to 2 days.

In this research, the digestion process corresponded to $\mathrm{pH}$ changes in the GI tract. Other degradation factors (i.e., enzymatic digestions) were not accounted for. The addition of enzymes, such as pepsin ${ }^{18}$ or pancreatin, ${ }^{19}$ to the digestive juice may be useful in evaluations of peptide-based or other digestible drugs.

\section{References}

1. Y. Konishi, Biosci. Biotechnol. Biochem., 2003, 67, 2297.

2. J. Alsenz and E. Haenel, Pharm. Res., 2003, 20, 1961.

3. A. M. Marino, M. Yarde, H. Patel, S. H. Chong, and P. V. Balimane, Int. J. Pharm., 2005, 297, 235.

4. S. Yoshitomi, K. Ikemoto, J. Takahashi, H. Miki, M. Namba, and S. Asahi, Toxicol. in Vitro, 2001, 15, 245.

5. D. R. Ciocca, S. A. W. Fuqua, S. Locklim, D. O. Toft, W. J. Welch, and W. L. McGuire, Cancer Res., 1992, 52, 3648.

6. S. Takayama, J. C. McDonald, E. Ostuni, M. N. Liang, P. J. A. Kenis, R. F. Ismagilov, and G. M. Whitesides, Proc. Natl. Acad. Sci. U. S. A., 1999, 96, 5545.

7. Y. Tanaka, K. Sato, M. Yamato, T. Okano, and T. Kitamori, J. Chromatogr., A, 2006, 1111, 233.

8. T. Tokuyama, S. Fujii, K. Sato, M. Abo, and A. Okubo, Anal. Chem., 2005, 77, 3309.

9. M. Goto, K. Sato, A. Murakami, M. Tokeshi, and T. Kitamori, Anal. Chem., 2005, 77, 2125.

10. H. Kimura, Y. Sakai, and T. Fujii, Membrane, 2009, 34, 304.

11. Y. Imura, Y. Asano, K. Sato, and E. Yoshimura, Anal. Sci., 2009, 25, 1403.

12. Y. Imura, K. Sato, and E. Yoshimura, Anal. Chem., 2010 , 82, 9983.

13. T. K. H. Chang, G. F. Weber, C. L. Crespi, and D. J. Waxman, Cancer Res., 1993, 53, 5629.

14. M. K. Kajanti, S. O. Pyrhönen, and A. G. Maiche, Eur. J. Cancer, 1993, 29, 863.

15. J. Kawasaki, "The Japanese Pharmacopoeia," 15th ed., 2006, Ministry of Health, Labour and Welfare, Tokyo, Japan, 104.

16. J. O'Brien, I. Wilson, T. Orton, and F. Pognan, Eur. J. Biochem., 2000, 267, 5421.

17. K. Ikeda, K. Yoshisue, E. Matsushima, S. Nagayama, K. Kobayashi, C. A. Tyson, K. Chiba, and Y. Kawaguchi, Clin. Cancer Res., 2000, 6, 4409.

18. L. R. Johnson, Annu. Rev. Physiol., 1985, 47, 199.

19. S. Calsamigla and M. D. Stern, J. Anim. Sci., 1995, 73, 1459. 